\title{
Performance of Jatropha curcas L. in Semi-arid Zone: Seed Germination, Seedling Growth and Early Field Growth
}

\author{
Sharif AHAMAD ${ }^{1}$, Soumai Kant JOSHI ${ }^{1 *}$, Mohommad ARIF², Zakwan AHMED² $^{2 *}$ \\ ${ }^{1}$ Defence Institute of Bio-Energy Research, Project Site-Chichondi Patil, Abmednagar, 414 201, \\ Maharashtra, India; skantjoshi@gmail.com ( ${ }^{*}$ corresponding author) \\ ${ }^{2}$ Defence Institute of Bio-Energy Research, Goraparao, Haldwani, 263 139, Uttarakhand, India \\ ("Present address: Directorate of Management Services, DRDO HQ, New Delhi, India)
}

\begin{abstract}
There is a lack of information on basic agronomic properties of Jatropha curcas L. (jatropha) cultivation on the marginal lands in the semi-arids. Evaluation of agronomic performance of identified elite strains of J. curcas in marginal lands would be of paramount importance for addressing gap areas in their agronomic properties and subsequently for harnessing their optimum economic potentials. The present study undertook the task of analysing the growth performance of a high oil bearing elite strain of $J$. curcas-DARL-2 in degraded land in semi-arid zone of Deccan Plateau, India. While undertaking the assessment of growth performance of elite strain DARL-2, two other native (wild) strains (namely AHN-1 and AHN-2) of J. curcas were also considered so that a comparative evaluation could be carried out. The role of gypsum was also investigated on J. curcas in the nursery stage as well its carry over effects on growth performance of transplanted trees in the field. Two types of substrates, gypsum-treated soil (GS) and untreated soil (SL) were used for growing seedlings of all the three jatropha strains. Seedlings (120-days-old) of DARL-2 exhibited greater plant height, collar diameter and number of branches but root length was greater in the local strains. In the second year of field transplantation, DARL-2 strain exhibited significantly $(p<0.05)$ greater plant height and number of branches/plant. No carry over effects of gypsum treatment were observed in field transplanted plants as none of the growth parameters significantly varied among the substrate types.
\end{abstract}

Keywords: agronomic performance, biodiesel, biofuel crops, gypsum treatment, semi-arid agro-ecosystems

\section{Introduction}

Jatropha curcas L. (physic nut), a small tree or a woody shrub of Central American origin is a notably valuable biofuel crop. With its seeds bearing 30 to $40 \%$ oil content (King et al., 2009) that can be easily converted into biodiesel, J. curcas has emerged as a promising biofuel crop. Biodiesel obtained from jatropha meets international standards (Azam et al., 2005) and is reported to exhibit better performance than conventional petroleum diesel (Mandpe et al., 2005). Because of the above-mentioned properties and applications and its great adaptability to arid and semi-arid environments (Abou Kheira and Atta, 2009), potential for wasteland reclamation, mitigating environmental problems, supporting socio-economic development (Francis et al., 2005), short gestation period and being unpalatable to grazers, J. curcas remains a preferred feedstock for bio-diesel production. Therefore, standardization of agronomic properties for growing jatropha on marginal lands is highly desirable. Furthermore, testing the suitability of the elite clones of jatropha in marginal lands is also important for obtaining profuse yield.

Although jatropha exhibits considerable survival in marginal lands, obtaining profuse oil yields under such conditions may not be possible (Moore et al., 2011).
Realizing the role of fertilizers in thriving cultivation of jatropha, research on identifying fertilizer $(\mathrm{N}, \mathrm{P}, \mathrm{K})$ requirements have been undertaken (Mohapatra and Panda, 2011) though the number of such studies is less. In addition to the fertilizers, there are certain substances, which affect the growth of plants. Apart from its important role as a soil amendment, gypsum $\left(\mathrm{CaSO}_{4} \cdot 2 \mathrm{H}_{2} \mathrm{O}\right)$-a source of sulphur (Hoeft et al., 1985) is reported to possess several growth and yield promoting properties for plants (Viator et al., 2002; Toma et al., 1999; Sanderson et al., 1996) by undertaking significant changes in soil environments. As such, the role of sulphur, a fourth most important nutrient required for crop productivity, is critical for oilseed crops (Tandon, 1986). Therefore, studying the role of gypsusm in influencing the growth and yield of $J$. curcas is desirable.

In the recent years, several elite genotypes of $J$. curcas have been identified worldwide. In the Indian context, DARL-2 (IC No. 569095), one of the elite strains of J. curcas bearing $36.5 \%$ oil content, has been identified as promising lines by a committee constituted by the Ministry of New and Renewable Energy, Govt. of India. The strain DARL-2 was collected from Uttarakhand, India. Keeping in view the high oil content of the strain DARL2 , the present study envisaged to undertake its preliminary 
170

agronomic evaluation in the semi-arid agro-ecological zone in Deccan Plateau, India. Moreover, in order to undertake comparative analysis of the growth performance of DARL-2 strain on a typical marginal land in the semiarid zone of Deccan Plateau, two of the locally growing wild strains of $J$. curcas were also considered for growth performance evaluation studies. Further, considering the growth and yield promoting functions of gypsum, the present study also tested the effect of gypsum in promoting early seedling growth in nursery and subsequently the performance of transplanted seedlings of the selected elite strain vis a vis locally growing strain in the field.

The present study attempted to assess growth performance of J. curcas strain DARL-2 along with two locally growing strains based on their seed germination, seedling growth in nursery, and field performance of the transplanted plants. Furthermore, the effect of gypsum in influencing seedling growth in nursery and subsequently its carry over effect on transplanted plants was also studied.

\section{Materials and methods}

\section{Study site}

The present research work was carried out at the Defence Institute of Bio-Energy Research (DIBER) Project Site, Chichondi Patil, Ahmednagar, Maharastra, India (185' N; 745ㄴ ' E; $708 \mathrm{~m}$ a.s.l.). The study site represented a typical marginal land of the hot semi-arid ecosystem of the Deccan Plateau. The experimental field was an undulating degraded pasture with shallow black soil having low fertility levels (N-245.0 kg/ha, P-3.6 kg/ha and organic carbon-0.38\%). In addition to this, occurrence of boulders and rocks were frequent throughout the pasture. Perennial grasses that grow luxuriantly during the rainy season (June to September) were the dominant natural vegetation. These grasses were harvested during November-December for hay production. Mild and dry winters, hot and humid summers and low annual rainfall (300 to $550 \mathrm{~mm}$ ) are characteristics of the climate of the region. Mean annual temperature of the region was $26-27^{\circ} \mathrm{C}$.

\section{Collection of seeds}

Seeds of jatropha stain DARL-2 were collected in December 2009 from DIBER Project Site, Secunderabad, Andhra Pradesh (India), where mass-scale plantations of the strain DARL-2 have been established. However, seeds of the representative local strains of J. curcas were collected in December 2009 from naturally growing plants from two sites Nandur, district Beed, Maharashtra (hereinafter termed as AHN-1) and Aathwad, district Ahmednagar, Maharashtra (hereinafter termed as AHN-2) located nearly 3 and $5 \mathrm{~km}$ respectively from the study site. The local collection sites were situated at a distance of nearly five $\mathrm{km}$ from each other. Collected seeds were kept in muslin cloth bags and stored at room temperature until utilized for experimental work.

\section{Seed germination and nursery growth performance}

The seed germination experiment was conducted using two types of substrates. The first set contained the normal soil and the other set was the same soil with gypsum added. Gypsum-treated soil substrate were prepared by applying agriculture grade gypsum at the rate of 10 tons/ha to a selected plot in the study site. After removing boulders and grass residues, calculated amount of gypsum was uniformly applied to the soil in the 30-cm-deep tilled plot, which was then left for six months. At a distance of $3 \mathrm{~m}$ from the gypsum treated plot, another plot was marked and tilled after the removal of stones and grass residues in order to get untreated soil. The soils $(0-15 \mathrm{~cm}$ depth) from the gypsum-treated as well as that from the untreated adjacent plot were collected and used for seed germination experiment. Farm yard manure (FYM) was added in 1:1 ratio $(\mathrm{v} / \mathrm{v})$ to both the types of substrates. Polythene bags (1.0 kg capacity) were filled with each substrate. Prior to sowing, the seeds were treated with a systemic fungicide carbendazim for five minutes and were soaked in tap water for 24 hours. Seeds were sown (one seed per each polythene bag) on 15 June 2010. Mean monthly maximum and minimum temperatures during the experiment period (June to September) were $30.8^{\circ} \mathrm{C}$ and $24.4^{\circ} \mathrm{C}$ respectively. Daily observations were made to record the data on seed germination (percentage) until the fifteenth day after sowing. After 120 days, plant height $(\mathrm{cm})$, collar diameter $(\mathrm{mm})$ and root length $(\mathrm{cm})$ were recorded. Watering $(100$ $\mathrm{ml} /$ plant) was done on alternate days from emergence to 30 days after sowing. Thereafter, $200 \mathrm{ml} /$ plant water was applied on every fourth day until $60^{\text {th }}$ day after sowing. For the remaining period, watering $(200 \mathrm{ml} /$ plant $)$ was done at weekly intervals. Weeding was done by hands. The seed germination experiment was conducted in a complete randomized design (CRD). There were three replicates for each strain sown in each of the substrate types. In each replicate, there were 25 seeds.

\section{Growth performance in field}

Nursery seedlings (120-days-old) (hereinafter termed as plants), of $J$. curcas were transplanted into the field on October 2010. For the field experiment only one of the two local strains (i.e., AHN-2) was considered for comparative evaluation of growth performance along with the elite strain DARL-2 as the strain AHN-1 did not perform optimally in nursery stage. In order to analyze the carry over effect of the substrate types (i.e., GS and SL), in which the plants were grown in nursery stage, the nursery origin of the plants of both the strains were maintained at the time of their plantation in the field. Plants were transplanted into the degraded pasture. Each plant was transplanted in a $45 \mathrm{~cm} \mathrm{x} 45 \mathrm{~cm} \mathrm{x} 45 \mathrm{~cm}$-sized pit at a spacing of $3 \mathrm{~m} \times 3 \mathrm{~m}$. To each plant, two kg FYM and $100 \mathrm{~g} \mathrm{di}-$ ammonium phosphate (DAP) (IFFCO, India; $46 \% \mathrm{P}$ and $18 \% \mathrm{~N}$ ) was provided at the time of plantation. In addition to this, five gram phorate granules (Insecticides India 
Ltd., New Delhi) were also placed in each pit in order to prevent infestation of pests. A basin of one meter diameter was prepared around each plant in order to undertake time to time required intercultural practices like, weeding and hoeing. Rest of the space across the plantation field was kept undisturbed, i.e., grasses were allowed to grow in the pasture. Although adequate soil moisture was present at the time of plantation, water (approximately 15 liters/ plant) was applied to the plants immediately after transplanting. Irrigation (approximately 15 liters/plant) was also applied once in November 2010 and March 2011. In order to promote lateral branch formation, first pruning (at a height of $30 \mathrm{~cm}$ from ground), was done in first year in February 2011, when plants were dormant. Plants grew rapidly until October (2011) and shed their leaves during November (2011) and remained dormant during the winters (December to February). In order to enhance branch formation in the second year, a second pruning was done by cutting the branches, developed after the first pruning, at a height of $40-45 \mathrm{~cm}$ from ground in February 2012. In the second year of growth in the field, plants were irrigated once in January 2012 and April 2012. During the rainy season, urea (50 g/plant) (IFFCO, India; $46 \% \mathrm{~N}$ ) was applied twice to the plants (in first week of July and August, 2012) in order to provide nitrogen fertilization for plant growth. The experiment was conducted in a randomized complete block design (RCBD). There were three replicates (with five plants each) for each of the strains and substrate types. Plant height $(\mathrm{cm})$, collar diameter $(\mathrm{mm})$ and number of branches/plant were recorded after two years in the field in October 2012.

\section{Data analysis}

Data were subjected to two-way analysis of variance (ANOVA) for determination of significance. Data scored as percentage were subjected to arcsine transformation (Snedecor and Cochran, 1967) before statistical analysis and converted back to percentage for presentation in the figure.

\section{Results}

\section{Seed germination and nursery growth performance}

Among the strains, maximum seed germination was observed in AHN-2 (77.3\% in GS), followed by DARL-2 ( $72 \%$ in SL) and AHN-1 (36\% in GS) (Fig. 1A). There were no significant differences in seedling height among the strains or between the substrate types (Fig. 1B). Maximum seedling height $(44.5 \mathrm{~cm})$ was observed in the strain DARL-2 grown in SL (Fig. 1B). Among all the strains, collar diameter was greater for DARL-2 $(25.8 \mathrm{~mm})$ than the local strains (Fig. 1C). DARL-2 strain produced the greatest number of branches/plant (0.9 branches in GS) among all the strains (Fig. 1D). More number of branches were formed in GS than SL. Although root length of seedlings did not vary significantly neither among the strains nor between the substrates, maximum root length was recorded in AHN-1 (39.3 cm in GS) followed by DARL-2 $(36.9 \mathrm{~cm}$ in SL) and AHN-2 (32.9 cm in GS) (Fig. 1E).
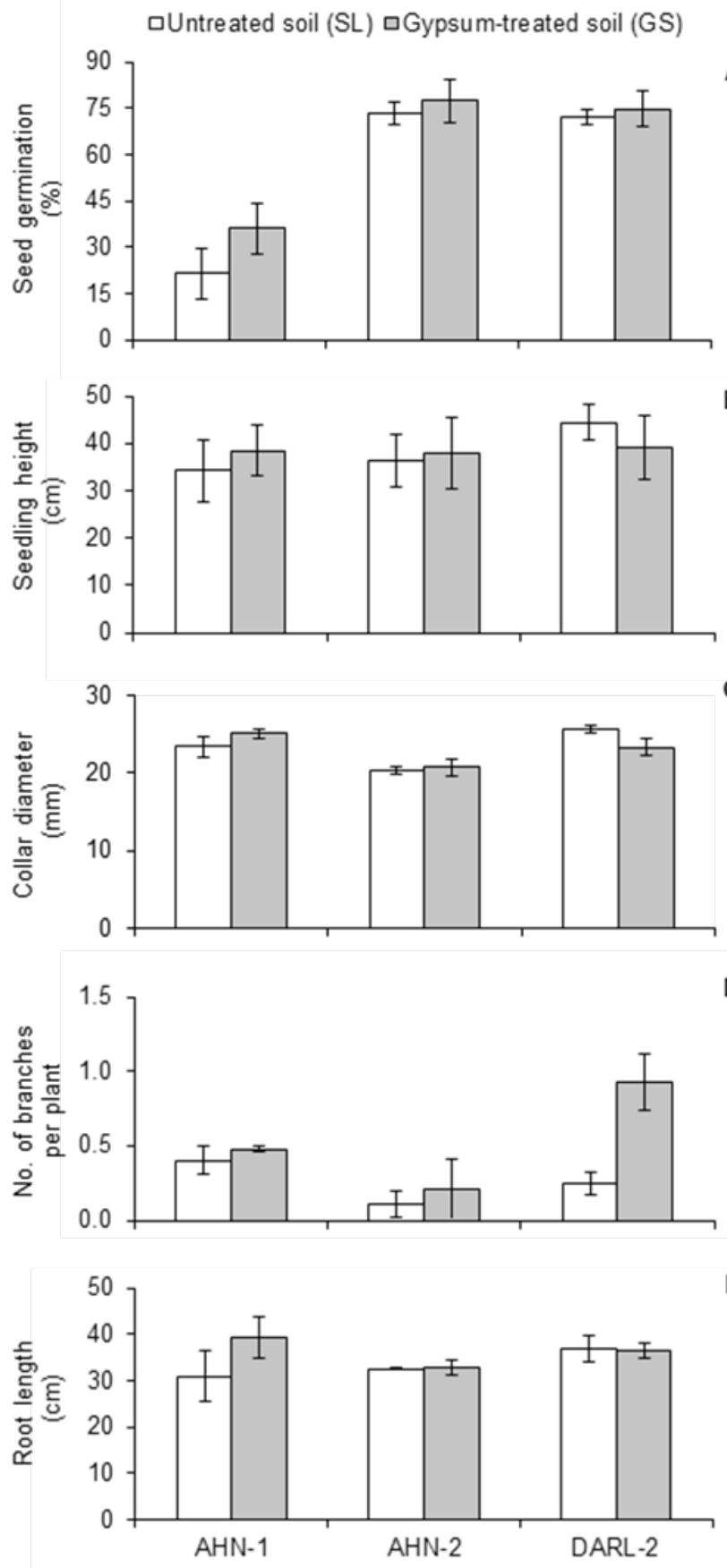

Fig. 1. Seed germination (A); seedling height (B); collar diameter (C); Number of branches/plant (D) and root length (E) of 120-days-old seedlings of elite strain (DARL-2) and local strains (AHN-1 and AHN-2) of J. curcas grown on untreated and gypsum-treated soil. Vertical bars represent \pm S.E. of means. 
172

\section{Field performance}

For evaluation of growth performance in the field, only one of the two local strains (AHN-2) was considered along with DARL-2 strain as the strain AHN-1 exhibited relatively very low seed germination percentage in comparison to the other two strains. Substrate types, on which the plants were grown in nursery stage, did not influence any of the three growth parameters after two years of field transplantation (Fig. 2). After two years of field transplantation, DARL-2 strain, grown in GS, had greater plant height $(121.7 \mathrm{~cm})$ than AHN-2 $(113.0 \mathrm{~cm})$ grown in GS (Fig. 2A). Plants of the strain DARL-2 grown in GS had slightly thicker stems with a collar diameter of $57.1 \mathrm{~mm}$ compared to AHN-2 (54.6 mm) in GS (Fig. 2B). DARL2 strain grown in GS substrate produced the most number of branches/plant (18.1 branches) among all the treatments (Fig. 2C).

口Untreated soil (SL) םGypsum-treated soil (GS)
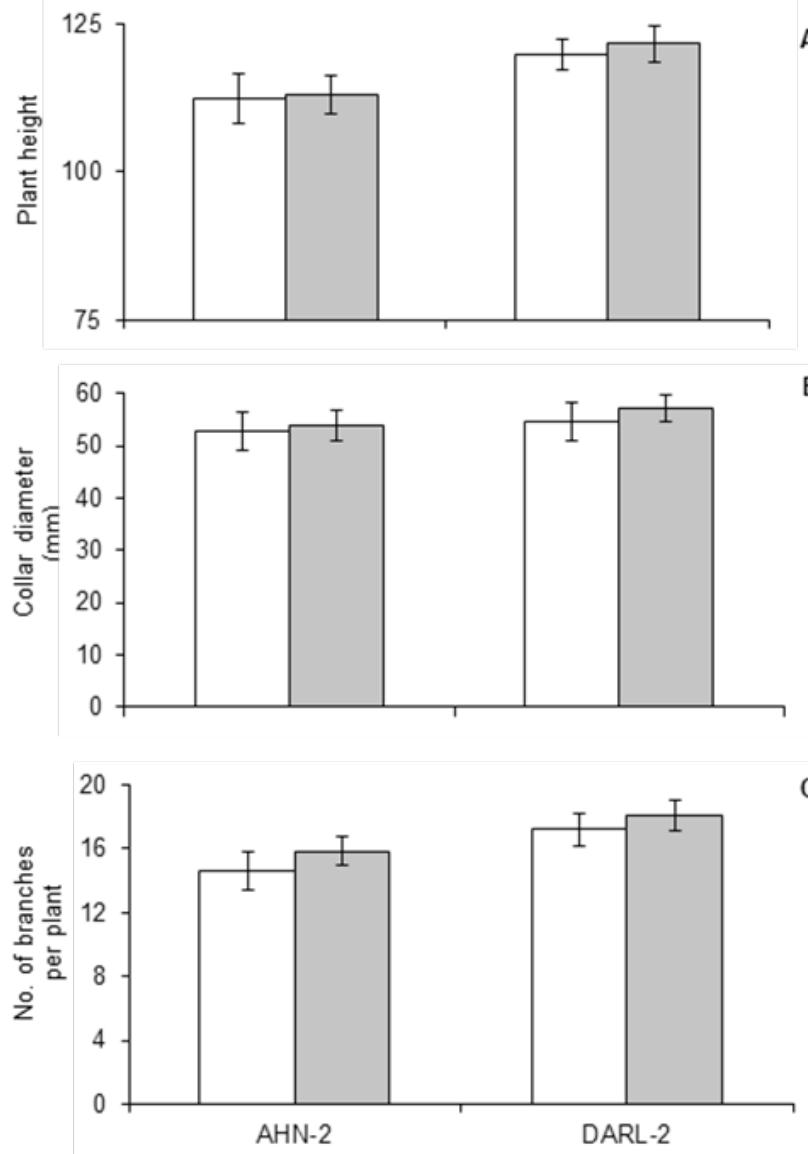

Fig. 2. Growth performance of plants of elite strain (DARL-2) and local strain (AHN-2) of $J$. curcas after two years of field transplantation: Plant height (A); Collar diameter (B); Number of branches/plant (C). Seedlings of both the strains were grown on untreated and gypsum-treated soils. Vertical bars represent \pm S.E. of means

\section{Discussion}

Seed source variation in seed germination and seedling growth of J. curcas has been reported earlier (Ginwal et al., 2005). Seed germination percentage in the present study were quite variable $(21.3 \%$ to $88.7 \%)$ among the strains. Successful seed germination ensures successful establishment of plants (Gorai and Neffati, 2007), suggesting that the seed germination (68\%) observed in the elite strain DARL-2 might influence its establishment in semi-arid zone of Deccan Plateau. Although, seeds of DARL-2 strain possessed good germination properties, Kumari et al. (2010) described that up to $70 \%$ seed germination can be achieved in one-year-old seeds by using plant growth regulators.

Height and collar diameter of 120-days-old seedlings of $J$. curcas strains in the present study were higher than those reported by Ghosh and Singh (2011) for 180-daysold seedlings of J. curcas grown from seeds collected from different provenances of semi-arid zone. In terms of seedling height, DARL-2 strain performed optimally at the study site. This is reflected from the comparable height attained by seedlings of strain DARL-2 to those of the local strain AHN-2. Furthermore, collar diameter was significantly $(p<0.01)$ greater in seedlings of DARL-2 (Fig. 1C). J. curcas is a stem succulent plant, in which succulent stem performs functions of balancing small water losses of the leaves during drought period (Maes et al., 2009). In this way, thicker shoots formed in DARL-2 in the present study might have the potentials to perform optimally in the semi-arid climate. Although a number of studies on seedling growth of J. curcas have been reported (Ginwal et al., 2005; Zaidman et al., 2010; Ghosh and Singh, 2011), no study has described the number of branches formed during seedling growth stage. After field transplantation, seedlings with well-developed branching system may attain optimum canopy architecture, important for seed yield, relatively earlier than unbranched seedlings. In the present study nearly one branch ( 0.9 branches) (significantly higher than both the local strains) was formed per plant (seedling) in DARL-2 strain grown in GS substrate (Fig. 1D). More importantly, the number of branches/ plant was significantly $(p<0.05)$ higher in GS than SL for both the strains.

To the best of our knowledge, this is the first study that has investigated the role of gypsum on the seedling growth of J. curcas. Different patterns of response of gypsum have been reported on growth and yield of different crops. Gypsum treatment to the soil is reported to increase yield of low bush blueberry (Sanderson et al., 1996), wheat and sorghum (Thomas et al., 1995) and corn and alfa-alfa (Toma et al., 1999). However, Viator et al. (2002) could not obtain any response of gypsum on yield and root growth in sugarcane and described that short duration 
use of gypsum was the probable reason for such response. In the present study, the short duration (only once) use of gypsum might be the cause for no or partial effect on growth of J. curcas seedlings.

Results of the growth performance of $J$. curcas plants after second year of their field transplantation revealed that the strain DARL-2 performed optimally as it exhibited significantly $(p<0.05)$ greater plant height and number of branches/plant than the local strain AHN-2 (Fig. 2). Branch length and number of branches are considered as important characters for selection of J. curcas especially when it is cultivated under agroforestry systems (Mohapatra and Panda, 2010). The number of branches formed in second year of field plantation in J. curcas strains DARL-2 in the present study was much higher than those reported by Saikia et al. (2009) in two-year-old plants, raised from rooted cuttings of different accessions. Furthermore, Behera et al. (2010) could only achieved up to 13.2 branches/plant under different interventions including application of vesicular arbuscular mycorrhiza (VAM) and other bio-fertilizers in two-year-old plants of J. curcas. The stem girth of plants of strain DARL-2 were similar to those reported by Saikia et al. (2009). The substrate types, on which the plants of both the strains were grown during nursery stage, did not significantly influence the field performance of transplanted plants suggesting no carry over effect of gypsum treatment.

\section{Conclusions}

Findings of this study revealed that Jatropha strain DARL-2 has exhibited considerable seed germination rates and comparable growth performance in the nursery stage to those of the local strains. Addition of gypsum could only affect the formation of greater number of branches/plant that too only in the nursery stage and had no significant effect on influencing branch number in the transplanted trees in the field. In field transplanted trees of strain DARL-2, significantly greater plant height and number of branches/plant were observed. These attributes of field transplanted trees of strain DARL-2 suggest that it could be a promising strain for efficient cultivation of jatropha in semi-arids. However, data on subsequent vegetative and reproductive growth as well as on yield attributes of the plantation would be of paramount importance for drawing stronger conclusions for suitability of DARL-2 for the semi-arid region.

\section{Acknowledgements}

Authors are thankful to the technical team of DIBER Project Site, Ahmednagar for providing the assistance during the course of study. Officer In-charge, DIBER Project Site, Secunderabad, India is gratefully acknowledged for providing jatropha seeds.

\section{References}

Abou Kheira AA, Atta NMM (2009). Response of Jatropha curcas L. to water deficits: Yield, water use efficiency and oilseed characteristics. Biomass Bioenergy 33:1343-1350.

Azam MM, Waris A, Nahar NM (2005). Prospects and potential of fatty acid methyl esters of some non-traditional seed oils for use as biodiesel in India. Biomass Bioenergy 29:293302.

Behera SK, Srivastava P, Tripathi R, Singh JP, Singh N (2010). Evaluation of plant performance of Jatropha curcas L. under different agro-practices for optimizing biomass-A case study. Biomass Bioenergy 34:30-41.

Francis G, Edinger R, Becker K (2005). A concept for simultaneous wasteland reclamation, fuel production, and socio economic development in degraded areas in India: need potential and perspectives of Jatropha plantations. Nat Resour Forum 29:12-24.

Ghosh L, Singh L (2011). Variation in seed and seedling characters of Jatropha curcas L. with varying zones and provenances. Tropical Ecol 52(1):113-122.

Ginwal HS, Phartyal SS, Rawat PS, Srivastava RL (2005). Seed source variation in morphology, germination and seedling growth of Jatropha curcas Linn. in Central India. Silvae Genetica 54:76-80.

Gorai M, Neffati M (2007). Germination responses of Reaumuria vermiculata to salinity and temperature. Ann Appl Biol 151:53-59.

Hoeft RG, Sawyer JE, Venden Heuvel RM, Schmitt MA, Brinkman GS (1985). Corn response to sulphur on Illinois soils. J Fertilizer Issues 2:95-104.

King AJ, He W, Graham IA, Cuevas JA, Freudenberger M, Ramiaramanana D (2009). Potential of Jatropha curcas as a source of renewable oil and animal feed. J Exp Bot 60:28972905.

Kumari M, Patade VY, Arif M, Ahmed Z (2010). Effect of IBA on seed germination, sprouting and rooting in cuttings for mass propagation of Jatropha curcas L strain DARL-2. Res J Agric Biologic Sci 6(6):691-696.

Maes WH, Achten WMJ, Reubens B, Raes D, Samson R, Muys B (2009). Plant-water relationships and growth strategies of Jatropha curcas L. seedlings under different levels of drought stress. J Arid Environ 73:877-884.

Mandpe S, Kadlaskar S, Degen W, Keppeler S (2005). On road testing of advanced common rail diesel vehicles with biodiesel from Jatropha curcas plant. Soc Automotive Eng Inc 26:356-364.

Mohapatra S, Panda PK (2010). Genetic variability on growth, phenological and seed characteristics of Jatropha curcas L. Not Sci Biol 2(2):127-132.

Mohapatra S, Panda PK (2011). Effect of fertilizer application on growth and yield of Jatropha curcas L. in an aeric tropaquept of eastern India. Not Sci Biol 3(1):95-100. 
174

Moore K, Greenhut S, Vendrame W (2011). Greenhouse production of Jatropha, a potential biofuel crop. Hortechnology 21(2):93-97.

Saikia, SP, Bhau BS, Rabha A, Dutta SP, Choudhari RK, Chetia M, Mishra BP, Kanjilal PB (2009). Study on accession source variation in morpho-physiological parameters and growth performance of Jattopha curcas. Linn. Curr Sci 96(12):1631-1636.

Sanderson KR, Carter MR, Ivany JA (1996). Effects of gypsum on yield and nutrient status of native lowbush blueberry. Can J Plant Sci 75:361-366.

Snedecor GW, Cochran WG (1967). Statistical Methods. The Iowa State University Press, Iowa.

Tandon HLS (1986). Sulphur research and agriculture production in India, $2^{\text {nd }}$ Ed. Fertilizer Development and Consultation, New Delhi, 76-77 p.
Thomas GA, Gibson G, Nielsen RGH, Martin WD, Radford BJ (1995). Effect of tillage, stubble, gypsum, and nitrogen fertilizer on cereal cropping on a red-brown earth in southwest Queensland. Aust J Exp Agric 35:997-1008.

Toma M, Sumner ME, Weeks G, Saigusa M (1999). Long-term effects of gypsum on crop yield and subsoil chemical properties. Soil Sci Soc Am J 63:891-895.

Viator RP, Kovar JL, Hallmark WB (2002). Gypsum and compost effects on sugarcane root growth, yield, and plant nutrients. Agron J 94:1332-1336.

Zaidman BZ, Ghanim M, Vaknin Y (2010). Effect of seed weight on seed vigour and early seedling growth of Jatropha curcas, a biodiesel plant. Seed Sci Technol 38:757-766. 